\title{
Technological Response of Wild Macaques (Macaca fascicularis) to Anthropogenic Change
}

\author{
Lydia V. Luncz ${ }^{1,2}$ (D) Magdalena S. Svensson ${ }^{2,3}$ • \\ Michael Haslam ${ }^{2}$ Suchinda Malaivijitnond ${ }^{4,5}$. \\ Tomos Proffitt ${ }^{2} \cdot$ Michael Gumert ${ }^{2,6}$
}

Received: 21 March 2017 / Accepted: 22 June 2017 /Published online: 29 August 2017

C) The Author(s) 2017. This article is an open access publication

\begin{abstract}
Anthropogenic disturbances have a detrimental impact on the natural world; the vast expansion of palm oil monocultures is one of the most significant agricultural influences. Primates worldwide consequently have been affected by the loss of their natural ecosystems. Long-tailed macaques (Macaca fascilularis) in Southern Thailand have, however, learned to exploit oil palm nuts using stone tools. Using camera traps, we captured the stone tool behavior of one macaque group in Ao Phang-Nga National Park. Line transects placed throughout an abandoned oil palm plantation confirmed a high abundance of nut cracking sites. Long-tailed macaques previously have been observed using stone tools to harvest shellfish along the coasts of Thailand and Myanmar. The novel nut processing behavior indicates the successful transfer of existing lithic technology to a new food source. Such behavioral plasticity has been suggested to underlie cultural behavior in animals, suggesting that long-tailed macaques have potential to
\end{abstract}

Handling Editor: Joanna M. Setchell

Electronic supplementary material The online version of this article (https://doi.org/10.1007/s10764-0179985-6) contains supplementary material, which is available to authorized users.

Lydia V. Luncz

Lydia.Luncz@anthro.ox.ac.uk

1 School of Anthropology and Museum Ethnography, University of Oxford, Oxford OX2 6PE, UK

2 School of Archaeology, University of Oxford, Oxford OX1 2PG, UK

3 Department of Social Science, Oxford Brookes University, Oxford OX3 0BP, UK

4 Department of Biology, Faculty of Science, Chulalongkorn University, Bangkok 10330, Thailand

5 National Primate Research Center of Thailand, Chulalongkorn University, Saraburi, Thailand

6 School of Humanities and Social Sciences, Nanyang Technological University, Singapore 637332, Singapore 
exhibit cultural tendencies. The use of tools to process oil palm nuts across multiple primate species allows direct comparisons between stone tool using nonhuman primates living in anthropogenic environments.

Keywords Anthropogenic influence - Behavioral flexibility - Macaca fascicularis . Nut cracking · Tool use

\section{Introduction}

The rapid expansion of humans across the globe has affected almost every part of the natural environment. Large-scale processes, such as increases in pollution and rates of climate change, may be combined with more local effects, including habitat destruction, and the introduction of monocultures and exotic species (Sih 2013). These anthropogenic effects can have negative outcomes for animals, especially if the effects are so rapid or extensive that biological adaptations such as phenotypic changes or niche modifications are insufficient to create adaptations due to natural selection (Jezkova and Wiens 2016). One potential buffer is behavioral plasticity, which permits individuals to adjust rapidly to local changes ahead of any phenotypic adjustments (Slabbekoorn and Ripmeester 2008). Anthropogenic changes in the natural habitat of animals can therefore also be used to understand behavioral flexibility and cognition. Behavioral responses to environmental changes can also provide guidelines for conservation efforts (Hockings et al. 2015).

A common human response to environmental threats has been to search for behavioral, and more specifically technological, solutions (Hoffert et al. 2002). We have little evidence that other tool-using species have followed a similar path of increased tool use in the face of anthropogenic change. More commonly, on the contrary, human activities negatively affect tool-using taxa. For example, logging is one potential cause of the absence of stick tool use among chimpanzees (Pan troglodytes schweinfurthii) of the East African Sonso community (Gruber 2013).

Tool use is rare in nonhuman primate species, and stone tools are used only by some groups of Western chimpanzee (Pan troglodytes verus: Boesch and Boesch 1983; Matsuzawa et al. 2011), bearded capuchin monkeys (Sapajus libidinosus: Fragaszy et al. 2004; Proffitt et al. 2016), and long-tailed macaques (Macaca fascilularis: Gumert and Malaivijitnond 2012; Malaivijitnond et al. 2007). Stone tools are invaluable when studying responses to changing conditions over time, as they leave longlasting evidence in the home range of the respective species, preserving past behaviors in the habitat (Luncz et al. 2015). Using modern archaeological techniques, it is becoming possible to interrogate the past tool-using habits of these primate species (Carvalho and McGrew 2012; Haslam et al. 2009, 2016a, 2016b).

Long-tailed macaques (Macaca fascicularis) are omnivorous primates with high dietary plasticity that exploit a wide variety of shellfish, nuts, and other encased food in coastal areas of Thailand and Myanmar (Gumert et al. 2009; Gumert and Malaivijitnond 2012). The variety of prey targeted by long-tailed macaques has been observed to exceed that seen in other tool-using primates 
(Gumert et al. 2009; Tan et al. 2015). The arrival of anthropogenic factors such as farming and domesticated dogs has, however, disrupted access to suitable food items, resulting in threats to macaque tool use traditions (Gumert et al. 2013).

Oil palm nuts (Elaeis guineensis) are considered a valuable high-calorie food source rich in proteins, fat, and vitamins (Sundram et al. 2003). The global expansion of oil palm monocultures has led to widespread clearing of natural forests worldwide, with an accompanying loss of species richness (Fitzherbert et al. 2008). Here we report technological oil palm exploitation by island-dwelling wild macaques in Ao PhangNga National Park, Thailand. Macaques in this park live in a hybrid zone of common (Macaca fascicularis) and Burmese (M. F. aurea) long-tailed macaques (Bunlungsup et al. 2016; Fooden 2006). This group has learned to crack open oil palm nuts using stone tools, following human introduction of oil palm into their habitat in the early 2000s. The recent inception of this behavior offers a valuable primatological and archaeological resource to document directly the development of a primate tool use behavior in a new ecological setting.

\section{Methods}

We conducted fieldwork in February and October 2016 on Yao Noi Island in Ao Phang-Nga National Park, Thailand (Fig. 1b). Our field site, Lobi Bay, is located on the northern shore of the island $\left(8^{\circ} 10.838^{\prime} \mathrm{N}, 98^{\circ} 37.746^{\prime} \mathrm{E}\right)$. Yao Noi Island is a hilly tropical forest island with an area of ca. $45 \mathrm{~km}^{2}$. The research site consists of an intertidal zone, a sandy beach ca. $5 \mathrm{~m}$ wide, and steep coastal forest (Fig. 1b). Within the forest there is an abandoned and overgrown oil palm plantation, the trees of which still regularly produce fruits. Both long-tailed and pig-tailed macaques (Macaca leonina) range within the field site.

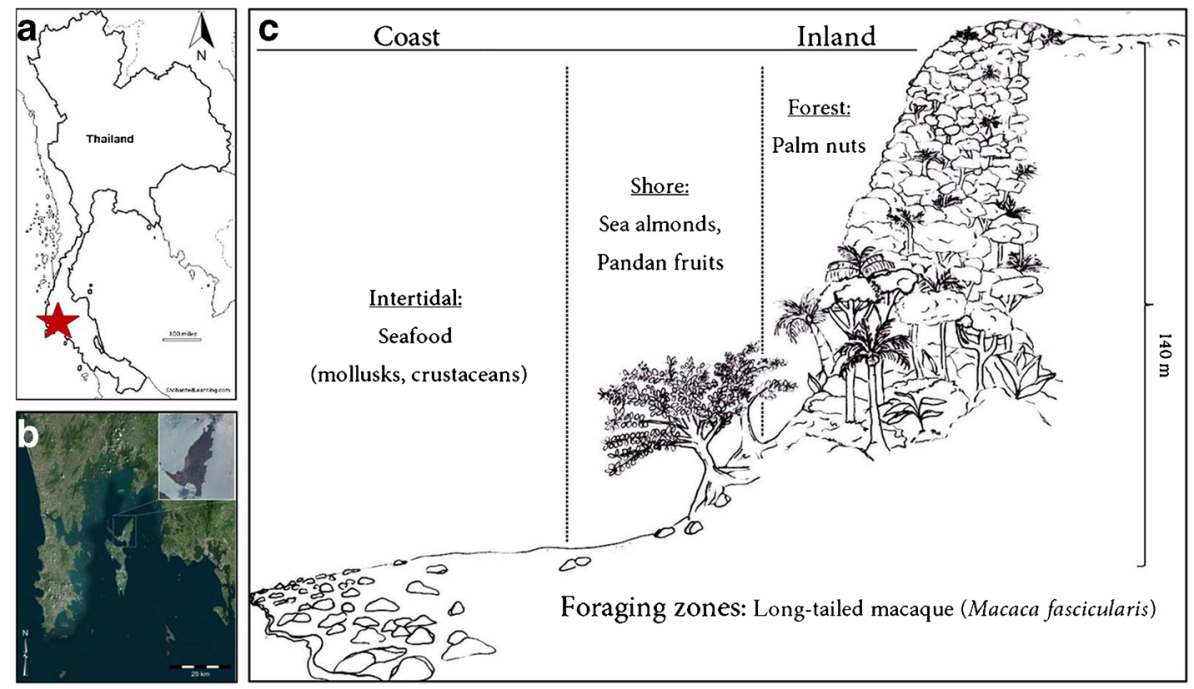

Fig. 1 Study site on Yao Noi Island. a Field site. Location of Ao Phang-Nga National Park in Thailand. b Location of Yao Noi Island within the park. c Schematic illustration of topographic tool-assisted foraging zones of long-tailed macaques in Thailand. (Illustrator: Kathleen Reinhardt). 
The long-tailed macaques at Lobi Bay are not habituated to the presence of humans. Initial observations of these macaques confirmed frequent shellfish cracking using stone tools along the intertidal shoreline. In addition, they use stones to crack open sea almonds (Terminalia catappa) along the shore, above the intertidal zone, as seen at other macaque tool use sites (Falotico et al. 2017). Following initial findings of potential macaque oil palm nut-cracking sites with broken nutshells and stone hammers at anvils (Fig. 2), we set up 12 Bushnell HD trophy camera traps at 10 previously used anvils within the abandoned oil palm plantation, distributed from the shoreline up to ca. $120 \mathrm{~m}$ above sea level. At each camera site/anvil, we provided oil palm nuts from nearby active plantations, as the oil palm trees at the field site were not producing nuts at the time of the study. We visited the sites every second day and provided new nuts whenever they were depleted.

To assess the availability and densities of raw materials, tool numbers, and oil palm trees we placed line transects within the abandoned oil palm plantation that was included in, but did not equal, the home range of the macaque group under study. The plantation was located within steep terrain, pervaded with cliffs and canyons. To survey the maximum area in the abandoned palm oil plantation, we arranged line transects in a zig-zag pattern, with insurmountable obstacles dictating the number of changes of direction in our line transects. Whenever a dead end was encountered we altered the direction of the transect by 45 degrees and continued sampling. This method resulted in a total of 13 line transects, surveying a total length of $1600 \mathrm{~m}$.

We defined hammerstones as portable rocks with clear use-wear in the form of central depressions, and use damage along their edges, found within a maximum distance of $50 \mathrm{~cm}$ of an anvil (Fig. 2a, c-e). We defined anvils as fixed limestone outcrops with traces of use on their horizontal planes, and broken nut shells located

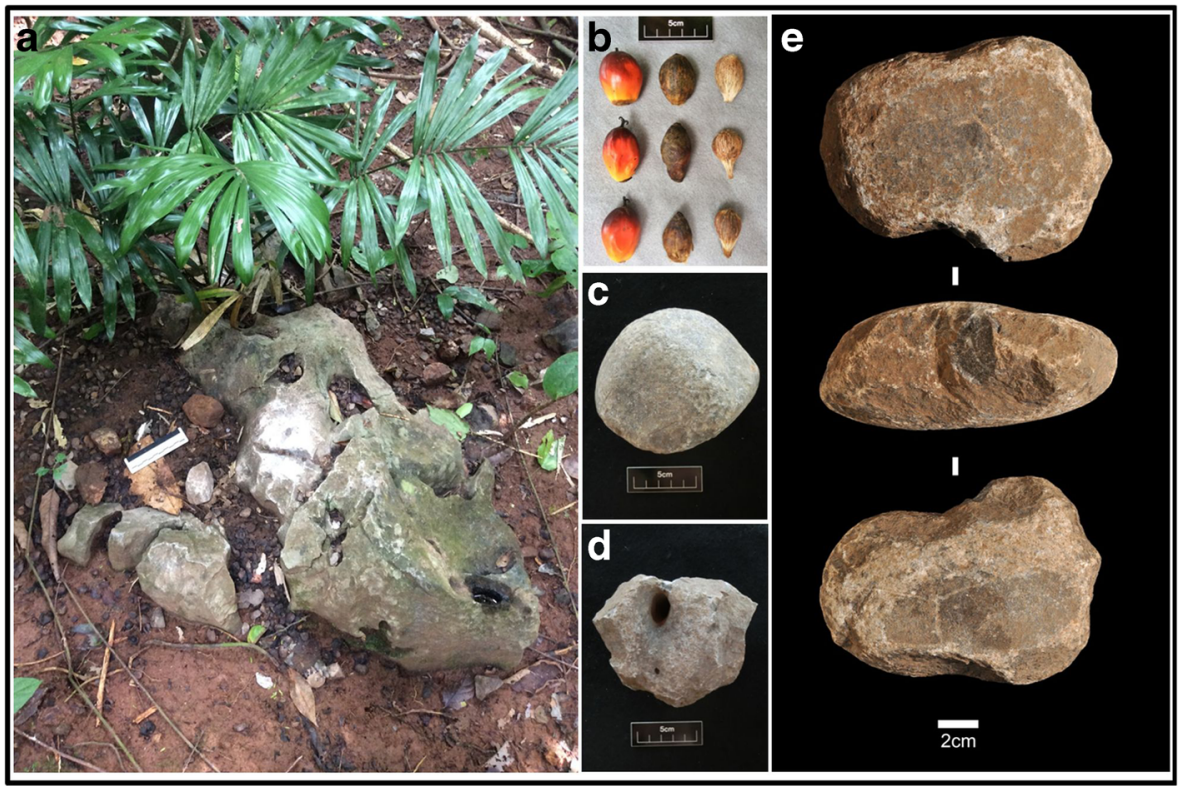

Fig. 2 Macaque oil palm nut cracking site. a Used anvil, with stone hammerstone assemblages. b Three different ripeness stages of oil palm nuts consumed by macaques. c, d, e Used hammerstones. 
within $50 \mathrm{~cm}$ circumference (Fig. 2a). We recorded hammerstone weight, dimensions, and material within $1 \mathrm{~m}$ either side of the transects, as well as anvils and their distance to the nearest nut tree. To compare weights between tools we log-transformed the weights due to a strong left skewed distribution of the samples. We also estimated the density of oil palm trees by counting their abundance within $5 \mathrm{~m}$ either side of the transect. To calculate densities, we used the formula $D=n / 2 L w$, where $n=$ number of objects, $L=$ total length of transect, and $w=$ strip width.

\section{Ethical Note}

Research was conducted using noninvasive observational data collection on natural nut cracking behavior in wild macaques. This research has been approved by the Institutional Animal Care and Use Committee, NTU, Singapore (ARF SBS/NIE-A0210). The Department of National Parks, Wildlife and Plant Conservation issued the permission to conduct research in the National Park (Permit Reference Number: DNP0907.4/ 22663, issued on October 31, 2016; the valid duration is October 1, 2016-September $30,2018)$. In addition, the research adhered to the legal requirements of Thailand.

\section{Results}

All camera traps combined recorded a total of $529 \mathrm{~min}(8 \mathrm{~h}$ and $49 \mathrm{~min}$ ) of macaque oil palm nut cracking behavior over 21 days. Once the macaques realized that nuts were available at the anvils they visited almost every day. Each camera trap frequently recorded tool use of long-tailed macaques. The footage demonstrated that the group in the monitored home range consisted of both male and female macaques of all age classes. As the group is not habituated to human presence we were not able to clearly identify individuals and precise evaluation of group size therefore was not possible. However, the average macaque group usually has ca. 20-30 individuals (Fooden 1995), and our footage suggests that the observed group ranges within these numbers too. Adult and juvenile macaques of both sexes consumed oil palm nuts, as we are not yet able to identify individuals we conservatively will classify this behavior as habitually (sensu Whiten et al. 2001). The macaques first ate the oily mesocarp and then used a stone to crack the inner kernel-bearing shell. To do so, they selected a stone hammer near the anvil, placed one nut at a time on top of the anvil and struck the nut until it broke (Electronic Supplementary Material (ESM), Video S1). They then used their fingers and occasionally their teeth to extract the kernel from the broken shell. The obtained video footage suggests that tool use by adult group members attracts the interest of infants and juveniles, as they often were filmed in proximity to a tool user, closely watching the feeding behavior.

Whenever the macaques triggered the camera traps, tool use was recorded. This suggests that macaques visited the sites only for nut cracking. We never recorded an alternative extraction method of oil palm that did not use tools.

Available stones, used hammerstones, and used anvils were abundant along the line transects (Table I, Fig. 2). Following our definitions, objects identified as hammerstones and anvils showed clear percussive marks. The primary raw material 
Table I Encounter rates of wild macaque lithic technology on line transects, Lobi Bay, Yao Noi Island, Thailand

\begin{tabular}{|c|c|c|c|c|c|c|c|}
\hline & $\begin{array}{l}\text { Stones } \\
\text { (total) }\end{array}$ & $\begin{array}{l}\text { Hammer- } \\
\text { stones }\end{array}$ & $\begin{array}{l}\text { Stones } \\
\text { (unused) }\end{array}$ & $\begin{array}{l}\text { Boulders } \\
\text { available (total) }\end{array}$ & $\begin{array}{l}\text { Anvils } \\
\text { (used) }\end{array}$ & $\begin{array}{l}\text { Unused } \\
\text { boulders }\end{array}$ & Oil trees \\
\hline Total no. & 448 & 338 & 110 & 251 & 210 & 41 & 66 \\
\hline Limestone & 350 & 252 & 98 & 238 & 197 & 41 & \\
\hline Laterite & 85 & 73 & 12 & 12 & 12 & 0 & \\
\hline Granite & 13 & 13 & 0 & 0 & 0 & 0 & \\
\hline Wood & - & - & - & 1 & 1 & - & \\
\hline Density $\left(\mathrm{m}^{2}\right)$ & 0.140 & 0.105 & 0.034 & 0.078 & 0.065 & 0.013 & 0.004 \\
\hline Measurements & Weight (g) & Weight (g) & Weight (g) & $\begin{array}{l}\text { Horizontal } \\
\quad \text { area }\left(\mathrm{cm}^{2}\right)\end{array}$ & $\begin{array}{l}\text { Horizontal } \\
\quad \text { area }\left(\mathrm{cm}^{2}\right)\end{array}$ & $\begin{array}{l}\text { Horizontal } \\
\quad \text { area }\left(\mathrm{cm}^{2}\right)\end{array}$ & $\begin{array}{r}\text { Distance anvil } \\
\text { to tree }(\mathrm{m})\end{array}$ \\
\hline Median & 206 & 217.5 & 195 & 357 & 390 & 120 & 5 \\
\hline Range & $56-5000$ & $59-5000$ & $56-3500$ & $21-17,600$ & $30-17,600$ & $21-1488$ & $0.1-20$ \\
\hline $\begin{array}{l}\text { 1st-3rd } \\
\text { quartile }\end{array}$ & $136-415.5$ & $136-411$ & $133-422$ & $162.5-828.5$ & $208-964$ & $56-304$ & $0.1-7.75$ \\
\hline
\end{tabular}

for hammerstones was limestone $(N=252 ; 74 \%)$, followed by laterite $(N=73 ; 22 \%)$ and granite $(N=13 ; 4 \%)$, mirroring the availability of these stone types on the landscape (Table I). Hammerstones and unused stones did not significantly differ in weight $(t=-0.56$, df $=171.43, P=0.57$, log-transformed due to a strong left skewed distribution of the samples). However, every granite stone we encountered had been used by the macaques. Overall, the macaques used a high percentage $(N=338 ; 75 \%)$ of the available stones as hammers. We located a mean of 1.61 hammerstones for each anvil (ESM S2).

Stone anvils were almost exclusively unmovable limestone outcrops $(N=197$; $94 \%)$, with the remainder formed of laterite $(N=12 ; 6 \%)$. The median distance from an anvil to the nearest tree was $5 \mathrm{~m}$ (ESM S2). We found one wooden anvil, with a distinct depression the size of an oil palm nut, during the transect surveys. Off-transect surveys around the identified nut-cracking sites located another two wooden anvils. Palm oil trees occurred at a density of one every $250 \mathrm{~m}^{2}$ along the transects.

\section{Discussion}

Our study showed that wild macaques on Yao Noi Island in the Ao Phang-Nga National Park frequently use stone tools to crack open oil palm nuts in an abandoned plantation. The tools selected for nut-cracking did not differ significantly from unused stone material found in the territory. This suggests that the macaques do not have a strong preference for a specific nut-cracking tool size. The high abundance of used tools and anvils indicates that the macaques are consuming this food source at a significant level, even though the arrival of oil palm nuts in Yao Noi Island is a recent event.

Dietary plasticity has been proven to be beneficial for long-tailed macaques, making them one of the most successful primate species, living in both undisturbed and urban areas where they exploit anthropogenic food sources (Gumert 2011). As part of this 
plasticity, macaques have been known for more than 100 years to use lithic technology (Carpenter 1887). At Lobi Bay, oil palm nuts were reportedly introduced by humans around 13 years ago (ca. 2004). Compared to their known exploitation of marine prey, this is a relatively short time span for the macaques to learn to exploit this novel food source. We hypothesize that long-tailed macaques have transferred an existing technological solution of harvesting encased shellfish within a coastal environment to exploit the nutritious nut of palm oil trees within an inland setting. Although currently benefiting from this new food source, oil palm nut cracking could potentially affect their natural foraging patterns on the coast. Future investigations will need to identify how this new tool use behavior influences the wider macaque range of tool-assisted foraging patterns, including its potential to diminish their natural sea food consumption and associated tool diversity.

The abundant and long-term evidence of macaque stone tool use in coastal settings (Carpenter 1887; Gumert and Malaivijitnond 2012; Haslam et al. 2016b; Malaivijitnond et al. 2007) suggests that stone tool use originated in the intertidal zone before expanding into the adjacent forest (Fig. 1c). Although this behavior is therefore likely to be relatively new in the tool repertoire of wild macaques, it offers the potential to study fine grained diachronic patterns of primate tool use, such as modification of the technology (choice of hammerstone size, morphology, raw material) and spatial and chronological development of the behavior. From a primate archaeological perspective this discovery is also significant, as this macaque behavior leaves a substantial and discrete archaeological record, one that is not affected by a daily intrusion from tidal forces. It therefore provides a new archaeological target for understating how primate tool use develops in relation to a sudden change of food source (Potts 2013). Further archaeological investigations are needed to assess whether the behavior was initiated close to the shore (where percussive activity is prevalent) and then spread inland, or whether it appeared across all oil palm producing regions essentially simultaneously. The effect and responses of wildlife to anthropogenic changes are sometimes difficult to observe directly when they are happening. Therefore, archaeological methods may help to reveal the potential loss or gain of a behavior by investigating past tool use. Future work must therefore focus on the targeted excavation of macaque oil palm nut cracking locations across the landscape.

The rapid uptake of oil palm nut cracking by the Yao Noi Island macaques shows their ability to take advantage of anthropogenic changes, and the recent establishment of this behavior indicates the potential for macaques to exhibit cultural tendencies. These characteristics permit comparisons with other technological, nut-cracking primates, such as chimpanzees and capuchin monkeys (Visalberghi et al. 2015). The comparison with chimpanzees goes further, however. As a result of the global expansion of oil palm monoculture, the same nut species, Elaeis guineensis, is exploited by stone tool using wild chimpanzees (Pan troglodytes verus) in Guinea (Biro et al. 2003; Humle and Matsuzawa 2004), alongside human populations that crack the same nuts (Sugiyama and Koman 1979). Investigating the similarities and differences in nut-cracking behavior, as well as the tools themselves, of primates using the same technology to access the same food source will allow the development of hypotheses regarding the evolution of hominin percussive technology. Percussive technology played an important role in the subsistence strategies of our early ancestors (Arroyo and de la Torre 2016; de la Torre and Mora 2005), and the earliest percussive behavior at Lomekwi 3 in West Turkana, Kenya, dated to 3.3 million years ago (Harmand et al. 2015), suggests that this behavior 
may span several hominin taxa. Identifying contemporary interspecies differences and similarities in the archaeological signature of primate percussive behavior may assist in developing hypotheses regarding the characteristics of hominin stone tool technology before the advent of the archaeological record.

\section{Data Availability}

The datasets generated during the current study are not publicly available because of ongoing analysis using the same dataset but are available from the corresponding author on reasonable request.

Acknowledgements We thank the National Research Council of Thailand and the Thai Department of National Parks, Wildlife, and Plant Conservation for their support. We thank Stephanie Poindexter and three anonymous reviewers for helpful comments on the manuscript and the PanAf Project, Christophe Boesch, Mimi Arandjelovic, Hjalmar Kuehl, and Paula Dieguez for providing camera traps. We thank Bang Ban and Bang Hem for logistical support in the field. This research was funded by European Research Council Starting Grant no. 283959. During writing L. V. Luncz was funded by the Leverhulme Trust Research Grant.

Open Access This article is distributed under the terms of the Creative Commons Attribution 4.0 International License (http://creativecommons.org/licenses/by/4.0/), which permits unrestricted use, distribution, and reproduction in any medium, provided you give appropriate credit to the original author(s) and the source, provide a link to the Creative Commons license, and indicate if changes were made.

\section{References}

Arroyo, A., \& de la Torre, I. (2016). Assessing the function of pounding tools in the early stone age: A microscopic approach to the analysis of percussive artefacts from beds I and II, Olduvai Gorge (Tanzania). Journal of Archaeological Science, 74, 23-34.

Biro, D., Inoue-Nakamura, N., Tonooka, R., Yamakoshi, G., Sousa, C., \& Matsuzawa, T. (2003). Cultural innovation and transmission of tool use in wild chimpanzees: Evidence from field experiments. Animal Cognition, 6(4), 213-223.

Boesch, C., \& Boesch, H. (1983). Optimisation of nut-cracking with natural hammers by wild chimpanzees. Behaviour, 83(3/4), 265-286.

Bunlungsup, S., Imai, H., Hamada, Y., Gumert, M. D., San, A. M., \& Malaivijitnond, S. (2016). Morphological characteristics and genetic diversity of Burmese long-tailed macaques (Macaca fascicularis aurea): Genetic diversity of tool using macaques. American Journal of Primatology, 78(4), 441-455.

Carpenter, A. (1887). Monkeys opening oysters. Nature, 36, 53.

Carvalho, S., \& McGrew, W. C. (2012). The origins of the Oldowan: Why chimpanzees (Pan troglodytes) still are good models for technological evolution in Africa. Cambridge: Cambridge University Press.

de la Torre, I., \& Mora, R. (2005). Technological strategies in the lower Pleistocene at Olduvai beds I \& II (Vol. 112). Liège: University of Liège Press.

Falotico, T., Spagnoletti, N., Haslam, M., Luncz, L. V., Malaivijitnond, S., \& Gumert, M. (2017). Analysis of sea almond (Terminalia catappa) cracking sites used by wild Burmese long-tailed macaques (Macaca fascicularis aurea). American Journal of Primatology, 29(5). doi:10.1002/ajp.22629.

Fitzherbert, E., Struebig, M., Morel, A., Danielsen, F., Bruhl, C., et al (2008). How will oil palm expansion affect biodiversity? Trends in Ecology \& Evolution, 23(10), 538-545.

Fooden, J. (1995). Systemactic review of Southeast Asian longtail macaques, Macaca fascicularis. Fieldiana Zoology, 81, 1-206.

Fooden, J. (2006). Comparative review of fascicularis-group species of macaques (primates: Macaca). Fieldiana Zoology, 107. doi:10.3158/0015-0754(2006)107[1:CROFSM]2.0.CO;2.

Fragaszy, D., Izar, P., Visalberghi, E., Ottoni, E. B., \& de Oliveira, M. G. (2004). Wild capuchin monkeys (Cebus libidinosus) use anvils and stone pounding tools. American Journal of Primatology, 64(4), 359-366. 
Gruber, T. (2013). Historical hypotheses of chimpanzee tool use behaviour in relation to natural and humaninduced changes in an East African rain forest1. Revue de Primatologie, 5. doi:10.4000/primatologie.1690.

Gumert, M. D. (2011). The common monkey of Southeast Asia: Longtailed macaque populations, ethnophoresy, and their occurrence in human environments. Monkeys on the Edge. Cambridge: Cambridge University Press.

Gumert, M. D., \& Malaivijitnond, S. (2012). Marine prey processed with stone tools by Burmese long-tailed macaques (Macaca fascicularis aurea) in intertidal habitats. American Journal of Physical Anthropology, 149(3), 447-457.

Gumert, M. D., Kluck, M., \& Malaivijitnond, S. (2009). The physical characteristics and usage patterns of stone axe and pounding hammers used by long-tailed macaques in the Andaman Sea region of Thailand. American Journal of Primatology, 71(7), 594-608.

Gumert, M. D., Hamada, Y., \& Malaivijitnond, S. (2013). Human activity negatively affects stone tool-using Burmese long-tailed macaques Macaca fascicularis aurea in Laem son National Park, Thailand. Oryx, 47(4), 535-543.

Harmand, S., Lewis, J. E., Feibel, C. S., Lepre, C. J., Prat, S., et al (2015). 3.3-million-year-old stone tools from Lomekwi 3, West Turkana, Kenya. Nature, 521(7552), 310-315.

Haslam, M., Hernandez-Aguilar, A., Ling, V., Carvalho, S., de la Torre, I., et al (2009). Primate archaeology. Nature, 460(7253), 339-344.

Haslam, M., Luncz, L., Staff, R. A., Bradshaw, F., Ottoni, E., \& Falotico, T. (2016a). Pre-Columbian monkey tools. Current Biology, 26, R515-R522.

Haslam, M., Luncz, L., Pascual-Garrido, A., Falótico, T., Malaivijitnond, S., \& Gumert, M. (2016b). Archaeological excavation of wild macaque stone tools. Journal of Human Evolution, 96, 134-138.

Hockings, K. J., McLennan, M. R., Carvalho, S., Ancrenaz, M., Bobe, R., et al (2015). Apes in the Anthropocene: Flexibility and survival. Trends in Ecology \& Evolution, 30(4), 215-222.

Hoffert, M. I., Caldeira, K., Benford, G., Criswell, D. R., Green, C., et al (2002). Advanced technology paths to global climate stability: Energy for a greenhouse planet. Science, 298(5595), 981-987.

Humle, T., \& Matsuzawa, T. (2004). Oil palm use by adjacent communities of chimpanzees at Bossou and Nimba Mountains, West Africa. International Journal of Primatology, 25(3), 551-581.

Jezkova, T., \& Wiens, J. J. (2016). Rates of change in climatic niches in plant and animal populations are much slower than projected climate change. Proceedings of the Royal Society B: Biological Sciences, 283(1843), 20162104.

Luncz, L. V., Wittig, R. M., \& Boesch, C. (2015). Primate archaeology reveals cultural transmission in wild chimpanzees (Pan troglodytes verus). Philosophical Transactions of the Royal Society, B: Biological Sciences, 370(1682), 20140348.

Malaivijitnond, S., Lekprayoon, C., Tandavanittj, N., Panha, S., Cheewatham, C., \& Hamada, Y. (2007). Stone-tool usage by Thai long-tailed macaques (Macaca fascicularis). American Journal of Primatology, 69(2), 227-233.

Matsuzawa, T., Humle, T., \& Sugiyama, Y. (2011). The chimpanzees of Bossou and Nimba. Primatology monographs. New York: Springer Science+Business Media.

Potts, R. (2013). Hominin evolution in settings of strong environmental variability. Quaternary Science Reviews, 73, 1-13.

Proffitt, T., Luncz, L. V., Falotica, T., Ottoni, E., de la Torre, I., \& Haslam, M. (2016). Wild monkeys flake stone tools. Nature, 539, 85-88.

Sih, A. (2013). Understanding variation in behavioural responses to human-induced rapid environmental change: A conceptual overview. Animal Behaviour, 85(5), 1077-1088.

Slabbekoorn, H., \& Ripmeester, E. A. P. (2008). Birdsong and anthropogenic noise: Implications and applications for conservation. Molecular Ecology, 17(1), 72-83.

Sugiyama, Y., \& Koman, J. (1979). Tool-using and -making behavior in wild chimpanzees at Bossou, Guinea. Primates, 20(4), 513-524.

Sundram, K., Sambanthamurthi, R., \& Tan, Y.-A. (2003). Palm fruit chemistry and nutrition. Asia Pacific Journal of Clinical Nutrition, 12(3), 355-362.

Tan, A., Tan, S. H., Vyas, D., Malaivijitnond, S., \& Gumert, M. D. (2015). There is more than one way to crack an oyster: Identifying variation in Burmese long-tailed macaque (Macaca fascicularis aurea) stonetool use. PloS One, 10(5), e0124733.

Visalberghi, E., Sirianni, G., Fragaszy, D., \& Boesch, C. (2015). Percussive tool use by Taï western chimpanzees and Fazenda Boa Vista bearded capuchin monkeys: A comparison. Philosophical Transactions of the Royal Society, B: Biological Sciences, 370(1682), 20140351.

Whiten, A., Goodall, J., McGrew, W. C., Nishida, T., Reynolds, V., et al (2001). Charting cultural variation in chimpanzees. Behaviour, 138(11/12), 1481-1516. 